\title{
Illness behaviour in elite middle and long distance
} runners

\author{
A Currie, S G Potts, W Donovan, D Blackwood
}

Newcastle General Hospital, Westgate Road, Newcastle upon Tyne NE4 6BE, United Kingdom

A Currie

\section{Department of}

Psychological

Medicine, Royal

Infirmary of

Edinburgh, Teviot

Row, Edinburgh

EH3 9YW, Scotland

S G Potts

University Health Service, Richard Verney Health Centre, University of

Edinburgh, 6 Bristo

Square, Edinburgh

EH8 9AL

W Donovan

Department of Psychiatry, University of Edinburgh, Kennedy Tower, Royal Edinburgh Hospital, Morningside Park, Edinburgh EH10 5HF D Blackwood

Correspondence to: Dr A Currie.

Accepted for publication 23 June 1998

\begin{abstract}
Objectives-To examine the illness attitudes and beliefs known to be associated with abnormal illness behaviour (where symptoms are present in excess of objective signs and pathology) in elite middle and long distance runners, in comparison with non-athlete controls.

Methods-A total of 150 athletes were surveyed using the illness behaviour questionnaire as an instrument to explore the psychological attributes associated with abnormal illness behaviour. Subjects also completed the general health questionnaire as a measure of psychiatric morbidity. A control group of 150 subjects, matched for age, sex, and social class, were surveyed using the same instruments.

Results-A multivariate analysis of illness behaviour questionnaire responses showed that the athletes' group differed significantly from the control group (Hotelling's $T$ : Exact $F=2.68 ; p=0.01)$. In particular, athletes were more somatically focused (difference between means $\mathbf{- 0 . 2 7}$; $95 \%$ confidence interval -0.50 to -0.03 ) and more likely to deny the impact of stresses in their life (difference between means 0.78 ; $95 \%$ confidence interval 0.31 to 1.25$)$. Athletes were also higher scorers on the Whiteley Index of Hypochondriasis (difference between means 0.76 ; 95\% confidence interval 0.04 to 1.48 ). There were no differences in the levels of psychiatric morbidity between the two groups.

Conclusions-The illness attitudes and beliefs of athletes differ from those of a well matched control population. The origin of these psychological attributes is not clear but those who treat athletes need to be aware of them.

(Brf Sports Med 1999;33:19-21)
\end{abstract}

Keywords: psychology; somatoform disorders; hypochondriasis; illness behaviour

For an elite athlete the consequences of even a minor illness or injury can be serious. At each major championship many leading athletes and several medal contenders have their performances affected in this way.

Attention has been drawn to the psychological impact of physical insults in individuals for whom health and fitness are of key importance. Little $^{1}$ describes the development of an atypical anxiety neurosis with a poor prognosis in such athletic individuals. An important feature of the neurosis he describes is the presence of hypochondriasis and somatisation. Hypochondriasis and somatisation can be understood as forms of abnormal illness behaviour. This concept was described and elaborated by Pilowsky ${ }^{2}$ as a means of illuminating areas of medicine where subjective symptomatology is present in a degree disproportionate to objective signs and pathology. Importantly Pilowsky's work also draws attention to the role that an individual's psychological attributes may have in explaining such a discrepancy. ${ }^{3}$

In sport there are two principal situations where subjective complaints can exceed objective evidence of pathology. These are in the overtraining syndrome and when recovery from injury is impaired or prolonged. The overtraining syndrome is a form of chronic fatigue induced by intense exercise, and in this syndrome it has been noted that physical signs and laboratory investigations are unhelpful and have been overrated. ${ }^{4}$ In contrast, psychological interventions have proved to be useful in diagnosis $^{5}$ and rehabilitation. ${ }^{6}$ Furthermore abnormal illness attitudes and beliefs are found in association with chronic fatigue syndrome ${ }^{7-9}$ and adversely affect outcome. ${ }^{10}$ Abnormal psychological attributes - for example, abnormal mood states-have been found in association with prolonged injury recovery, although in major studies of this association such abnormalities have been attributed to the extent of the initial injury. ${ }^{11}{ }^{12}$ However, the use of indirect measures of injury severity (time absent from sport) calls this conclusion into question, for such measures are unlikely to be independent of mood state and in fact may be highly dependent on it. This raises the question as to whether abnormal mood states influence illness behaviours and produce an apparent prolongation of injury recovery time.

The observation that the physically fit are prone to forms of abnormal illness behaviour especially where objective pathology is an inadequate explanation for subjective symptomatology has led us to examine the illness attitudes and beliefs of athletes. Specifically we have examined elite athletes in the expectation that they would be a homogeneous group for whom the consequences of injury or illness would be greatest.

\section{Methods}

A total of 150 elite middle and long distance runners were contacted through the database of a national sports promotion company and surveyed by postal questionnaire. This database is primarily used in the organisation of high quality track and road races within the United Kingdom and includes most of the 
Table 1 Age, sex, and class matching of athlete and control groups

\begin{tabular}{llll}
\hline & Athletes & Controls & Significance \\
\hline Mean (SD) age & $26.6(3.46)$ & $26.4(4.36)$ & NS $^{\star}$ \\
Male:female ratio & $64: 21$ & $28: 18$ & NS $^{\star \star}$ \\
Social class & & 35 & \\
$\quad$ I-IIIa & 72 & 3 & NS $^{\star \star}$ \\
IIIb-V & 3 & &
\end{tabular}

NS, Not significant.

${ }^{\star}$ Unpaired $t$ test.

$\star \star \chi^{2}$ test with Yates's correction.

country's leading middle and long distance runners. Athletes were selected at random from the database and no selection bias is thought to have occurred.

A control group of 150 subjects was selected with reference to the principal demographic variables known to influence illness behaviours (age, sex, and social class). Age and sex matching was achieved by selecting subjects from the practice list of a group general practice in south Edinburgh. Social class matching was less precise but was achieved by selecting a geographical area of Edinburgh which would reflect the expected skewing towards higher social classes of the athletes' group.

All subjects completed three questionnaires: a demographic inventory (recording age, sex, and occupation), the general health questionnaire (GHQ), and the illness behaviour questionnaire (IBQ). Athletes were also asked a series of questions relating to sporting performance including representative honours.

The GHQ is a reliable and validated self report screening instrument for psychiatric morbidity. ${ }^{13}$ The 30 item version was selected for its ease of use.

The IBQ examines the attitudes and beliefs that underpin abnormal illness behaviours. ${ }^{14}$ Its 62 items generate scores on seven subscales reflecting these attitudes and beliefs. With the exception of scale 3, high scores on each measure are associated with more abnormal illness attitudes and beliefs. Scale 1 (general hypochondriasis) refers to anxious concerns about one's state of health. Scale 2 (disease conviction) reflects strong convictions as to the presence of somatic pathology and a poor response to reassurance. Scale 3 (psychological versus somatic focusing) indicates the rejection of a psychological view of symptoms and a tendency to somatise concerns. Scale 4 (affective inhibition) indicates an impaired ability to communicate feelings, especially negative ones. Scale 5 (affective disturbance) reflects levels of anxiety and/or sadness. Scale 6 (denial) refers to a tendency to deny life stresses and to attribute problems to the effects of illness. Scale 7 (irritability) assesses the extent of interpersonal friction and angry feelings. The IBQ was developed from the Whiteley Index of Hypochondriasis, ${ }^{15}$ and a score is also obtained for this 14 item inventory.

All subjects who failed to respond to the original mailing were recontacted after 1 month. No further reminders were sent.

All data were analysed anonymously using standard parametric and non-parametric methods of analysis. A significance level of 0.05 was used throughout.

\section{Results}

Completed IBQs were returned by 85 (57\%) athletes and $46(31 \%)$ controls. There were no significant differences between these groups in any demographic variables (age, sex, and social class), with each group being young, predominantly male, and skewed towards higher social classes (table 1).

The group of athletes was made up of 62 runners $(73 \%)$ competing at middle distance events $(800-5000 \mathrm{~m})$ and $21(25 \%)$ who were participating in long distance events (10 000 $\mathrm{m}$, half-marathon, and marathon). Data were not available on two of the athletes. In all, 10 $(12 \%)$ of the athletes had competed in either the Olympic Games or World Championships, a further 25 (29\%) had competed at another major international event - for example, European Championships or World Cross-Country Championships - and 50 (59\%) were competing just below this level either as occasional internationals or at a high level of domestic competition.

GHQ data were used to compare the levels of psychiatric morbidity in each population. It has been suggested that sample means and standard deviations rather than case/non-case distinctions provide a more accurate portrayal of population psychiatric morbidity in populations where the prevalence is low. ${ }^{16}{ }^{17}$ When the data are summarised in this way no significant difference is found (mean (SD) GHQ score for the athletes $=3.46(4.63)$ and that for the controls $=4.41(5.34)$; Mann-Whitney $\mathrm{U}$ test; $\mathrm{p}>0.05)$.

Table 2 illustrates the seven IBQ subscale scores for the group of athletes and compares them with the control group. Whiteley Index of Hypochondriasis scores are also shown. A multivariate analysis of all seven subscales using Hotelling's two sample $\mathrm{T}$ statistic shows

Table 2 Comparison of illness behaviour questionnaire (IBQ) scores: athletes versus controls

\begin{tabular}{|c|c|c|c|c|}
\hline & Athletes $(n=85)$ & Controls $(n=46)$ & $\begin{array}{l}\text { Difference between means } \\
(95 \% \mathrm{CI})\end{array}$ & $p$ \\
\hline \multicolumn{5}{|l|}{ IBQ scales } \\
\hline 1 General hypochondriasis & $1.33(1.53)$ & $1.24(1.40)$ & $0.09(-0.44$ to 0.62$)$ & NS \\
\hline 2 Disease conviction & $1.31(0.94)$ & $1.20(1.09)$ & $0.11(-0.25$ to 0.47$)$ & NS \\
\hline 3 Psychological/somatic focusing & $1.93(0.69)$ & $2.20(0.62)$ & $-0.27(-0.50$ to -0.03$)$ & 0.03 \\
\hline 4 Affective inhibition & $2.51(1.92)$ & $2.28(1.95)$ & $0.22(-0.47$ to 0.92$)$ & NS \\
\hline 5 Affective disturbance & $0.94(1.36)$ & $1.13(1.24)$ & $-0.19(-0.66$ to 0.28$)$ & NS \\
\hline 6 Denial & $3.24(1.26)$ & $2.46(1.39)$ & $0.78(0.31$ to 1.25$)$ & 0.001 \\
\hline 7 Irritability & $1.48(1.33)$ & $1.15(1.19)$ & $0.33(-0.13$ to 0.79$)$ & NS \\
\hline Whiteley Index & $3.02(2.12)$ & $2.26(1.77)$ & $0.76(0.04$ to 1.48$)$ & 0.04 \\
\hline Multivariate analysis with Hotelling's $\mathrm{T} ; \mathrm{p}=0.01$ & & & & \\
\hline
\end{tabular}

NS, Not significant. 
that the two groups are significantly different in their responses. Subsequent univariate analysis comparing the mean scores on individual subscales shows that the athletes' group scores are significantly lower on the psychological versus somatic focusing subscale (scale 3) and significantly higher on the denial subscale (scale 6). Of the two measures of hypochondriasis (scale 1 and the Whiteley Index), the athletes' group are higher scorers on the latter measure only.

\section{Discussion}

The illness attitudes and beliefs of elite athletes differ from a control group matched for age, sex, and social class. In particular, athletes are more likely to reject a psychological viewpoint of illness, to somatise their concerns, and to deny the importance of life stresses. They also display a higher level of hypochondriacal concerns, as evidenced by their higher scores on the Whiteley Index of Hypochondriasis. Importantly these differences are not explained by higher levels of psychiatric morbidity, which are similar in both groups.

In a cross-sectional survey such as this, it is not possible to determine how these psychological attributes arise. It is not possible to say if athleticism and sporting activity lead to the evolution of these characteristics, if individuals with these characteristics are preferentially drawn to sport, or even if a third factor-for example, a personality trait - is associated with both sporting excellence and abnormal illness attitudes and beliefs. Regardless of how these attributes arise, their association with sporting prowess is important for several reasons.

Firstly, it is known that psychiatric morbidity is a potent influence on illness behaviour ${ }^{18}$ and it is important to be aware of the potential interaction between anxiety and/or depression and health attitudes and beliefs. The possibility of this type of interaction should be borne in mind when assessing and determining appropriate treatment for injured athletes who present with associated psychological symptoms, regardless of the origin of psychological distress.

Secondly, where specific psychological strategies for the rehabilitation of injured athletes have been proposed these have been based on observations on non-athlete populations, and the need for specific knowledge of the cognitions, mood, and behaviour of injured athletes has been highlighted. ${ }^{19}$ An important contribution in this area is an awareness of the health attitudes and beliefs of athletes (especially where these attributes relate to illness behaviours).
Thirdly, Singh and colleagues ${ }^{20}$ have drawn attention to the role that clinicians have to play in the origin and evolution of illness attitudes and beliefs. Perhaps it is in this sphere that the findings of this study have their greatest relevance. Many therapists in the field of sports medicine are themselves from a sporting background and may therefore be expected to share (and even to reinforce) the illness attitudes and beliefs of those they treat.

Finally, it should not be forgotten that knowledge of the particular health concerns of any individual, as well as his unique appraisal of his symptom, are an important part of an holistic approach to treatment and rehabilitation.

Thanks are due to Alistair Currie for his help in data collection. This study was funded by a research grant from the Scottish Sports Council.

1 Little JC. The athlete's neurosis: a deprivation crisis. Acta Psychiatr Scand 1969;45:187-97.

2 Pilowsky I. Abnormal illness behaviour. Br 7 Med Psychol 1969;42:347-51.

3 Pilowsky I. The concept of abnormal illness behaviour. Psychosomatics 1990;31:207-13.

4 Budgett R. The overtraining syndrome. BMf 1995;309: 465-8.

5 Raglin JS, Morgan WP. Development of a scale for monitoring training induced distress in athletes. Int $\mathcal{F}$ Sports Med 1994;15:84-8.

6 Hooper SL, Mackinnon LT, Howard A, et al. Markers for monitoring overtraining and recovery. Med Sci Sports Exerc 1995;27:106-12

7 Hickie I, Lloyd A, Wakefield D, et al. The psychiatric status of patients with the chronic fatigue syndrome. Brf Psychiatry 1990;156:534-40.

8 Schweitzer R, Robertson DL, Kelly B, et al. Illness behaviour of patients with chronic fatigue syndrome. F Psybehaviour of patients with chr
chosom Res 1994;38:41-9.

9 Trigwell P, Hatcher S, Johnson M, et al. 'Abnormal' illness Trigwell $\mathrm{P}$, Hatcher $\mathrm{S}$, Johnson $\mathrm{M}$, et al. 'Abnormal' illness
behaviour in chronic fatigue syndrome and multiple sclerosis. BMF 1995;311:15-18.

10 Wessely S, Sharpe M. Chronic fatigue, chronic fatigue syndrome and fybromyalgia. In: Treatment of functional somatic syndromes. Mayou R, Bass C, Sharpe M, eds. Oxford: Oxford University Press, 1995:285-312.

11 Smith AM, Stuart MJ, Wiese-Bjornstal DM, et al. Competitive athletes: pre-injury and post-injury mood state and self esteem. Mayo Clinic Proc 1993;68:939-47.

12 Smith AM, Scott SG, O'Fallon WM, et al. Emotional responses of athletes to injury. Mayo Clinic Proc 1990;65: re-50.

13 Goldberg DP, Blackwell B. Psychiatric illness in a suburban general practice. A detailed study using a new method of general practice. A detailed study using a

14 Pilowsky I, Spence ND. Manual for the illness behaviour questionnaire (IBQ). Adelaide: University of Adelaide, 1983

15 Pilowsky I. Dimensions of hypochondriasis. Br F Psychiatry 1967;113:89-93.

16 Banks MH, Clegg CW, Jackson PR, et al. The use of the General Health Questionnaire as an indicator of mental health in occupational studies. Fournal of Occupational Psychology 1980;53:187-94.

17 Goldberg D. Estimating the prevalence of psychiatric disorder from the results of a screening test. In: What is a case? Wing JK, Bebbington P, Robins NL, eds. London: Grant McIntyre, 1981:129-36.

18 Colgan S, Creed F, Klass H. Symptom complaints, psychiatric disorder and abnormal illness behaviour in patients with upper abdominal pain. Psychol Med 1988;18:887-92.

19 Smith AM, Scott SG, Wiese DM. The psychological effects of sports injuries: coping. Sports Med 1990;9:352-69.

20 Singh B, Nunn K, Martin J, et al. Abnormal treatment behaviour. Br f Med Psychol 1981;54:67-73. 